\title{
INTEGRAÇÃO DA DENDEICULTURA À AGRICULTURA FAMILIAR: UM ESTUDO DOS IMPACTOS SOCIOAMBIENTAIS E ECONÔMICOS NO POLO DE PRODUÇÃO CONCÓRDIA, PARÁ
}

\author{
A. M. S. GEMAQUE ${ }^{1}$, A. C. R. SOUSA ${ }^{2}$, N. E. S. BELTRÃO 3 \\ Universidade Federal do Pará ${ }^{1,2,3}$ \\ amanda.gemaque@yahoo.com.br ${ }^{1}$
}

Artigo submetido em 26/02/2018 e aceito em 18/11/2019 DOI: $10.15628 /$ holos.2019.7015

\section{RESUMO}

O presente trabalho teve como objetivo analisar os impactos socioambientais e econômicos causados pela expansão da dendeicultura em propriedades de agricultores familiares, no polo Concórdia de produção de dendê, localizado no Nordeste do Estado do Pará. A abordagem metodológica utilizada foi quali-quantitativa, com levantamento de dados a partir de formulários semiestruturados que foram aplicados a uma amostra de 19 agricultores familiares previamente selecionados dentro da área de estudo. A análise dos dados coletados foi realizada por meio de estatística descritiva, com auxílio do programa SPSS versão 20.0., e permitiu apontar, neste estudo de caso, dificuldades na adequação do cultivo do dendê ao modelo de mão- de-obra familiar, bem como uma pequena participação da atividade na geração de situações que comprometem a saúde humana e o meio ambiente, a exemplo da disposição final inadequada de resíduos sólidos perigosos, provenientes das embalagens vazias e laváveis de agrotóxicos. Como benefícios dessa integração, constatou-se o aumento na assistência técnica e capacitação dos agricultores. Como resultados do estudo, verificou-se a necessidade de políticas que ofereçam aos agricultores alternativas econômicas ao dendê, e que sejam também capazes de promover o desenvolvimento socioambiental das comunidades envolvidas. Por fim, ressalta-se que apesar da perspectiva econômica da dendeicultura, ainda se faz necessário avaliar as condições estruturais nas quais os agricultores familiares se encontram sob a ótica da sustentabilidade e inclusão social, especialmente na região Amazônica.

PALAVRAS-CHAVE: Óleo de Palma, Desenvolvimento regional, Comunidades rurais.

\section{INTEGRATION OF DENDEICULTURE TO FAMILY FARMING: A STUDY OF SOCIO- ENVIRONMENTAL AND ECONOMIC IMPACTS IN THE PRODUCTION POLE CONCORDIA, PARÁ}

\section{ABSTRACT}

The objective of this work was to analyze the socioenvironmental and economic impacts caused by the expansion of dendeiculture on family farmers' properties at the Concordia palm oil production site located in the Northeast of the State of Pará. The methodological approach used was qualitative and quantitative, with data collection from semi-structured forms that were applied to sample of 19 family farmers within the study area. The analysis of the collected data was made through descriptive statistics, with the aid of the SPSS software version 20.0., and allowed to point out, in this case study, difficulties in the adequacy of palm oil cultivation to the family labor model, as well as a small participation of the activity in the generation of income of the families. In addition, situations that compromise human health and
\end{abstract}

the environment have been identified, such as the inadequate final disposal of hazardous solid waste from the empty and washable agrochemical packaging. As benefits of this integration, there was an increase in the technical assistance and training of farmers. From the study results, it is highlighted the need for policies that offer farmers economic alternatives to palm oil, and that are also capable of promoting the socio- environmental development of the communities involved. Finally, it is worth noting that despite the economic perspective of dendeiculture, it is still necessary to evaluate the structural conditions in which family farmers find themselves under the perspective of sustainability and social inclusion, especially in the Amazon region.

KEYWORDS: Oil palm, Regional development, Rural communities. 


\section{INTRODUÇÃO}

O crescente rendimento da produção de dendê permitiu a rápida expansão da indústria do óleo de palma nas zonas tropicais da Ásia, África e América, sendo as principais bases produtivas localizadas na Malásia e Indonésia (Corley \& Tinker, 2015)

Segundo Brandão e Schoneveld (2015), o óleo de palma é o óleo vegetal mais comercializado no mundo devido a sua competitividade de preços e seus múltiplos usos que envolvem alto potencial para a produção de biodiesel, e alta capacidade substitutiva na produção de alimentos, produtos químicos industriais, cosméticos e produtos farmacêuticos.

Em relação a outras oleaginosas, além de ser considerada a palmeira de maior produtividade do mundo, o dendezeiro possui maior potencial mercadológico como produto industrial-oleaginosa (Lebid \& Henkes, 2015). Levando em consideração esses fatores, a estabilidade da oferta comparativamente alta e as fortes perspectivas de mercado em longo prazo, muitos governos, em especial na América Latina e África passaram a promover o cultivo do dendê em seu território (Brandão \& Schoneveld, 2015).

No Brasil, o dendê foi introduzido durante o período colonial pelos escravos africanos no litoral do recôncavo baiano, região na qual a planta encontrou as condições de solo e clima ideais para o seu desenvolvimento (Beltrão \& Oliveira, 2008). Porém, somente a partir da metade da década de 2000 que essa cultura passou a atrair investidores nacionais e internacionais como a Petrobrás e Vale, por conta das perspectivas econômicas no mercado de biodiesel (Brandão \& Schoneveld, 2015).

Sendo assim, estudos passaram a ser desenvolvidos para avaliar quais locais estariam mais aptos à dendeicultura no país, como por exemplo, o zoneamento agroecológico da cultura da palma de óleo em áreas desmatadas na Amazônia Legal, levando em consideração as aptidões edafoclimáticas exigidas para o cultivo. De acordo com os resultados desta pesquisa, os principais estados com aptidão para a produção do dendê são Rondônia (com 2.720.638 ha), Pará (2.327.674 ha) e Amazonas (com 1.461.375 ha), levando em consideração o nível de manejo no qual são empregadas práticas agrícolas com nível tecnológico médio (Ramalho, 2010).

Por conta das condições favoráveis, o estado do Pará vem aumentando a produção do dendê, possuindo a segunda maior lavoura de produção $(11,44 \%)$ em 2013, quando foi responsável por $83 \%$ da produção nacional (Fundação Amazônia de Amparo a estudo e pesquisa [FAPESPA] 2015). Esta tendência de expansão tem provocado mudanças no padrão de uso da terra na região, o qual tem buscado suprir o mercado de óleo de palma, muitas vezes à custa do não atendimento das exigências legais que garantiriam mais proteção nas áreas de Preservação Permanente e Reserva Legal, contribuindo assim com o aumento do desflorestamento (Backhouse, 2013).

Nesse sentido, o cultivo do dendê tem fundamentado a elaboração de políticas públicas tal como o Programa Nacional de Uso e Produção do Biodiesel, que teve como destaque a inserção da agricultura familiar na cadeia produtiva do dendê como ferramenta de inclusão social. Com isso, houve a integração de contingente significativo de pequenos agricultores familiares com a produção paraense de dendê baseada na perspectiva de elevação de renda e melhoria de vida. Porém, há 
controvérsias sobre as reais melhorias que a integração entre dendeicultura e agricultura familiar pode propiciar (Gemaque, Beltrão, Mesquita, \& Ferreira Filho, 2017).

Segundo estudos realizados por Nahum e Santos (2016) nos municípios de Moju, Acará, Tailândia, Tomé-Açu e Concórdia do Pará, a dendeicultura pode ocasionar problemas socioambientais que envolvem desde especulação mobiliária até o uso ilegal de terras, além de tornar os pequenos agricultores dependentes dessa monocultura. Neste sentido, é relevante investigar as mudanças territoriais provocadas por esta nova dinâmica e seus impactos sociais, econômicos e ambientais para a região Amazônica.

Esta pesquisa tem como objetivo analisar os impactos socioambientais e econômicos causados pela expansão da dendeicultura em propriedades de agricultores familiares no estado do Pará, tendo como área de estudo o Pólo Concórdia de produção de dendê.

\section{REVISÃO BIBLIOGRÁFICA}

2.1Área de ocorrência do óleo de palma.

O dendezeiro ou palma de óleo (Elaeis guineensis Jacq.) é uma palmeira de origem africana cultivada nas três principais regiões tropicais equatoriais: África, sudeste Asiático e na América Central e do Sul, sendo encontrado em seu estado silvestre, semi-silvestre ou cultivado (Corley \& Tinker, 2015).

A segunda espécie de dendê (E. Oleifera) originou-se na América do Sul ou América Central, e foi levada para outros continentes para fins de reprodução e pesquisa. No continente Americano, a palma de óleo despertou muito interesse e seu uso através do cruzamento de espécies de dendê é generalizado, mas seus rendimentos são muito pequenos. Atualmente, as indústrias na Colômbia e no Equador são as maiores da América (Corley \& Tinker, 2015).

Na África Oriental a cultura distribui-se de forma irregular em decorrência do clima seco nessa região e no sudeste, fazendo com que a safra apareça apenas em altitudes abaixo de 1000 metros, onde se encontram lagos ou cursos d'água com chuvas razoáveis. Em contrapartida, por conta das condições favoráveis, a cultura tem crescido com sucesso na África Ocidental (Verheye, 2010; Mitchell, 2010).

No sudeste asiático, a intensificação da plantação da palma ocorreu a partir da segunda guerra mundial devido a melhorias que facilitaram o transporte do óleo. Nessa região, a palmeira encontrou condições para que se adaptasse perfeitamente aos solos e clima, ultrapassando a produtividade das plantações africanas, principalmente em países como Indonésia e Malásia, que são responsáveis por $85 \%$ da produção mundial de óleo de palma (Albano, 2012; Food and Agriculture Organization of the United Nations [FAO] 2014).

2.2 Características e usos do dendê.

Atualmente o dendezeiro é considerado a principal fonte mundial de óleo vegetal devido à sua alta produtividade em pequenas áreas, alta capacidade de fixação de carbono, longo ciclo de 
exploração com cobertura permanente do solo e grande capacidade de geração de empregos, um a cada seis hectares (Pena, 2011).

É uma cultura típica da floresta tropical que requer solo profundo e condições climáticas estáveis, principalmente relacionadas ao fornecimento de luz e umidade, para um ótimo crescimento e produção. Qualquer alteração dessas condições pode reduzir seu rendimento. Desenvolve-se melhor em latitudes baixas (300 a 400 metros), porém em casos onde o microclima é favorável, existe a possibilidade de desenvolver-se em latitudes muito maiores (até 1300 metros) (Verheye, 2010).

Segundo Mitchell (2010), uma palmeira madura pode chegar a 20 metros de comprimento e produzir cachos que podem pesar de 40 a $50 \mathrm{~kg}$. A partir de $100 \mathrm{~kg}$ de cachos é possível produzir $22 \mathrm{~kg}$ de óleo de palma e 1,6 kg de óleo de palmiste. Dessa forma, em um hectare de plantação, a palmeira pode produzir mais de 20 toneladas de cachos que podem produzir 4 toneladas de óleo.

O fruto do dendê consiste em uma camada externa oleosa (o mesocarpo) com uma única semente ou amêndoa. O óleo de palma é derivado do mesocarpo e é utilizado principalmente como óleo de cozinha e o óleo de palmiste é derivado das sementes e usado em alimentos processados. Além disso, o óleo de palma também é usado na fabricação de sabão e cosméticos. A folhagem e a amêndoa triturada são processadas para alimentação de gado (Mitchell, 2010).

\subsection{0 dendê na Amazônia brasileira.}

No Brasil, os estudos sobre a viabilidade de implantação da dendeicultura tiveram seu marco inicial em 1950, a partir da parceria entre o governo brasileiro e o Institut de Recherches Pour Lês Huiles et Les Oleagineux (IRHO) que tinha como objetivo identificar áreas com condições edafoclimáticas favoráveis para o desenvolvimento do cultivo do dendê em escala agroindustrial (Cruz \& Rocha, 2007).

A aptidão edafoclimática ou pedoclimática de terras para o cultivo de uma determinada cultura é baseada na comparação entre a necessidade ecofisiológica da planta e a oferta ambiental da área onde se pretende implantá-la, de modo que a relação custo/benefício seja favorável. Essa metodologia baseia-se no fato de que cada espécie vegetal possui um conjunto de características de solo, relevo e clima, e outros fatores ambientais, no qual ela melhor se adapta e sua implantação exerce menor impacto negativo sobre o ambiente (Ramalho, 2010).

Dessa forma, a partir da identificação de condições favoráveis em áreas dentro da região amazônica e no sul da Bahia, considerou-se viável a implantação dos projetos de dendeicultura no Brasil, desde que fossem aplicadas as mesmas técnicas de manejo e adubação dos países precursores na produção da cultura (Nahum et al., 2014).

Em relação às áreas identificadas com viabilidade para o cultivo do dendê, a Amazônia foi considerada a mais promissora porque além de possuir excelentes condições edafoclimáticas, apresentava grande disponibilidade de terras aptas para o cultivo (Cruz \& Rocha, 2007).

Aliado a esses fatores, outro ponto importante que tornava a dendeicultura viável economicamente na região amazônica era a demanda de mercado por óleo de palma que crescia a 
nível mundial e a possibilidade do Brasil prover seu próprio mercado interno, ou seja, o cultivo do dendê representava uma alternativa socioeconômica para o país e para a Amazônia (Nahum et al., 2014).

Os primeiros projetos agroindustriais de óleo de palma instalados na Amazônia foram implementados na região nordeste do estado do Pará, na década de 1960 (Villela, Jaccoud, Rosa \& Freitas, 2014). Inicialmente, o cultivo da dendeicultura estabeleceu-se nos municípios de Ananindeua, Benevides, Santa Izabel do Pará e Santo Antônio do Tauá, nos quais as empresas já vinculavam suas atividades aos pequenos produtores (Carvalho, Nascimento \& Nahum, 2014).

A expansão do cultivo do dendê no nordeste paraense vem ocorrendo devido à boa aptidão agroclimática e à instalação de várias agroindústrias para o processamento da matéria-prima, bem como boa logística de ocupação territorial da agricultura familiar. Em decorrência de restrições ainda encontradas dessa expansão para novas áreas, as empresas vêm motivando a integração com os segmentos de agricultores familiares (Alves, Modesto, Magalhães \& Bandeira, 2016).

Os agricultores familiares foram introduzidos na cadeia produtiva do dendê a partir do Programa Nacional de Uso e Produção de Biodiesel (PNPB), criado em 2004, que apresentava como objetivo diferencial, em relação às outras iniciativas, a implantação de um programa sustentável, com inclusão social através da geração de emprego e renda para agricultura familiar (Silva, 2013).

A inclusão social do agricultor familiar ocorre por meio do selo combustível social que é concedido ao produtor de biodiesel mediante o cumprimento dos seguintes critérios estabelecidos pelo PNPB: (i) estabelecer contratos com agricultores familiares ou entidades representativas, (ii) prestação de assistência técnica sem custo aos agricultores, (iii) estimular o plantio de oleaginosas em áreas com zoneamento agrícola para a oleaginosa em questão e (iv) adquirir da agricultura familiar percentual mínimo de matéria-prima (10\% na região Norte) (Silva, 2013).

A partir do cumprimento desses critérios, as empresas produtoras de dendê adquirem benefícios oriundos de políticas públicas específicas voltadas para promoção comercial e produção de combustíveis, além da redução das alíquotas da contribuição para o PIS/PASEP e da COFINS incidentes sobre a importação e sobre a receita bruta auferida com a venda de biodiesel no mercado interno, de acordo com o 2o parágrafo do artigo 2 do decreto № 5.297 de 6 de dezembro de 2004 (Brasil, 2004).

Em 2010, foi lançado o Programa de Produção Sustentável da Palma de Óleo no Brasil que além de abordar a inclusão da agricultura familiar, estabeleceu regras definidas para a expansão da dendeicultura, incluindo proteção e recuperação do meio ambiente, investimentos e inovação tecnológica. A iniciativa consolida importantes instrumentos legais, como a limitação da expansão da produção somente em áreas já desmatadas, proibindo a derrubada de vegetação nativa para o plantio do cultivo de dendê (Soares, 2015).

Atualmente, o dendê vem sendo fortemente difundido nos municípios de Abaetetuba, Acará, Baião, Bonito, Bujaru, Castanhal, Concórdia do Pará, Igarapé- Açu, Moju, São Domingos do Capim, Santo Antônio do Tauá e Tomé-Açu no nordeste paraense com incentivo do Programa de Produção Sustentável da Palma de Óleo no Brasil (Alves et al., 2016). 


\subsection{INTEGRAÇÃO ENTRE INDÚSTRIA E AGRICULTURA FAMILIAR}

Os sistemas de integração entre as indústrias e agricultores familiares intensificaram-se a partir da década de 1970 e eram voltados, principalmente, para a engorda de animais de pequeno porte das cadeias produtivas de grandes indústrias como Sadia e Perdigão, além de estarem relacionados com a produção de grãos e acordos entre fumicultores e a indústria fumageira (Bruno, 2016).

Ao promoverem a integração das suas cadeias produtivas aos núcleos de agricultores familiares, através de relações contratuais, as indústrias contam com benefícios como a garantia do fornecimento em qualidade e quantidade de matéria-prima, recursos já disponibilizados pelos agricultores referentes a terra, mão-de-obra, e conhecimento tácito (Aquino, 2013).

As integrações produtivas podem apresentar semelhanças e diferenças em alguns aspectos. De modo geral, os agentes envolvidos nos sistemas de integração com as indústrias possuem acesso a treinamentos técnicos, tecnologia, crédito bancário e garantia de mercado. Apesar desses aparentes benefícios, grande parte das famílias precisam realizar outras atividades para complementar a renda.

Em estudo realizado em Santa Catarina sobre a integração com a suinocultura, $80 \%$ dos agricultores apontaram como principais vantagens da integração, a garantia de venda, renda fixa da atividade, mão-de-obra familiar, além do acesso a serviços diferenciados como o treinamento para lidar com o aproveitamento de dejetos (Vargas \& Spanevello, 2010).

Ainda segundo os autores, os entrevistados afirmaram que a produção de suínos não é a única atividade geradora de renda para o núcleo familiar, sendo a produção de leite a atividade complementar mais utilizada. Relatou-se também a insatisfação com o preço pago pela produção, a necessidade de mão-de-obra extra e as altas exigências de produção como as principais desvantagens da integração ao sistema.

As vantagens em relação a segurança de venda de produção e garantia de assistência técnica também são relatadas por Zaluski e Marques (2015) em pesquisa realizada sobre a integração entre agricultores e indústrias da avicultura de corte. As desvantagens ressaltadas também envolvem o pequeno valor pago pela indústria integradora e a dependência de insumos e assistência técnica.

Situação semelhante é verificada no caso da fumicultura, conforme mostrado por Redin (2010) que destaca como fatores determinantes para a inserção dos agricultores nas agroindústrias fumageiras, o acesso à assistência técnica, garantia de compra de safra e o domínio da tecnologia do sistema de produção. Em contrapartida, há ressalvas sobre a dependência dos agricultores em relação a essas indústrias.

A adesão de agricultores familiares ao cultivo do dendê, assim como os exemplos de sistemas integrativos citados anteriormente, também apresenta benefícios envolvendo a segurança de mercado consumidor e fornecimento de insumos. Da mesmo modo que em relação às desvantagens os agricultores ressaltam o baixo valor da produção e a dependência em relação à empresa (Piraux, Rapiau \& Timone, 2017). 
No que diz respeito aos pontos divergentes entre as integrações produtivas citadas e a dendeicultura, cabe ressaltar que nas atividades envolvendo a suinocultura, avicultura e fumicultura a maioria dos agricultores possuía contato prévio com a atividade, enquanto que para os agricultores integrados à cadeia do dendê, o cultivo da palmeira se apresenta como uma prática até então desconhecida.

2.5 Impactos socioambientais do cultivo do dendê.

As críticas em relação à expansão da dendeicultura no Pará estão relacionadas a aspectos sociais e ambientais, como a exploração de mão de obra sem vínculos empregatícios legais, ameaça às áreas quilombolas e à biodiversidade local, pouca garantia de retorno financeiro, risco de pragas e doenças, uso de agroquímicos, dependência com relação à agroindústria e transformação de comunidades tradicionais em produtores de dendezeiros (Homma, 2016).

O contrato de inclusão de agricultores familiares na cadeia produtiva do dendê provoca uma restruturação nas relações entre proprietário e terra, fazendo com que o agricultor perca autonomia sobre sua propriedade, onde a cultura é implantada, em decorrência do controle das etapas de trabalho por parte da empresa que determinam desde o tamanho da área destinada ao plantio (10 hectares) até a proibição do cultivo de culturas tradicionais nas linhas de produção do dendê (Dietz, Engels, Pye \& Brunnengrabe, 2015).

As empresas não permitem o cultivo integrado do dendê com outras culturas para que não haja implicações sobre a produção e consequentemente sobre os lucros gerados, o que acaba gerando uma dependência do agricultor em relação a este cultivo. Além disso, a conversão do óleo de palma para outros usos é complexa e cara, não configurando esta mudança de uso uma alternativa viável para o agricultor familiar, fazendo com o que o mesmo esteja dependente do setor por pelo menos 25 anos, período de produtividade do dendê (Dietz et al., 2015).

A participação dos agricultores familiares na cadeia produtiva do dendê contribuiu para a melhoria da renda das famílias participantes do projeto, porém houve o aumento da dependência de recursos agrícolas externos para a realização de suas atividades. De acordo com os autores, ainda que comunidades envolvidas com a produção da palma possuam condições econômicas favoráveis, estas não são suficientes para o atendimento de todas as dimensões do conceito de qualidade de vida (Gemaque et al., 2017).

Os impactos ambientais do cultivo do dendê estão relacionados aos impactos causados pelo cultivo de monoculturas. A monocultura consiste no cultivo de uma única espécie agrícola em determinada área ou região, sendo prejudicial ao solo devido ao desgaste e empobrecimento nutricional que a produção contínua de uma mesma espécie causa. Além disso, há a contaminação gerada pelo elevado uso de fertilizantes e agrotóxicos utilizados com a finalidade de repor nutrientes e combater as pragas que surgem em decorrência da uniformização das culturas (Zimmermann, 2009).

Fitzherbert et al. (2008) ressaltam que as monoculturas de dendê exigem o uso frequente de inseticidas, herbicidas e fertilizantes que podem ser escoados para os rios e impactar diretamente a biodiversidade aquática. Ao longo do tempo, poderiam não só de degradar habitats 
aquáticos, mas seriam capazes de formar desertos biológicos e colaborar para a fragmentação de áreas de florestas remanescentes.

Borges, Bonow, Silva, Rocha e Cezar-Vaz (2016) ressaltam que a produção de forma orgânica e o cultivo de policulturas são vistos como alternativas para a redução do uso de agrotóxicos. Além disso, é recomendado a introdução dos Equipamentos de Proteção Individual (EPI), o armazenamento e descarte corretos das embalagens desses produtos, a precaução em relação ao período de carência dessas substâncias e atenção quanto as orientações contidas nos rótulos e bulas de cada uma delas. Desse modo, o uso dos agrotóxicos de forma cautelosa pode diminuir os riscos de contaminação e consequentemente os impactos a todas as formas de vida.

\section{METODOLOGIA}

Este estudo tem uma abordagem quali-quantitativa, e utilizou métodos de pesquisa bibliográfica e levantamento de dados a partir de fontes primárias, através da aplicação dos formulários; e secundárias, tais como relatórios de institutos de pesquisa e contratos de adesão ao projeto dendê. Para o desenvolvimento do tema e alcance dos objetivos propostos, a metodologia adotada consistiu de 5 etapas: i) pesquisa bibliográfica sobre os temas fundamentais que embasam o arcabouço teórico conceitual e a posterior discussão dos resultados desta pesquisa; ii) definição da área de estudo e seleção dos produtores que compõem a amostra de pesquisa; iii) definição do instrumento de coleta de dados, com a estruturação do formulário para levantamento dos dados juntos aos produtores e empresas selecionados; iv) Pesquisa de campo, para coleta dos dados; v) Análise dos resultados e discussão.

\section{1Área de estudo.}

Dentre muitos Pólos de produção de dendê com agricultores familiares no estado optou-se por realizar este estudo no Pólo Concórdia, devido à facilidade em obter informações e entrar em contato com os agricultores por intermédio da secretária municipal de agricultura e de outros atores.

O pólo abrange os municípios de Concórdia do Pará, Bujaru, Acará e São Domingos do Capim (Figura 1). O zoneamento por "Pólos" é uma divisão administrativa realizada pela empresa BIOPALMA que atua na produção e beneficiamento de dendê na área de estudo desde os anos 2000.

Os quatro municípios que constituem o Pólo Concórdia estão localizados no nordeste paraense, estando três deles (Concórdia, Bujaru e Acará) inseridos na região de integração Rio Capim e um (São Domingos do Capim) inserido na região de integração Guamá (Pará, 2010).

HOLOS, Ano 35
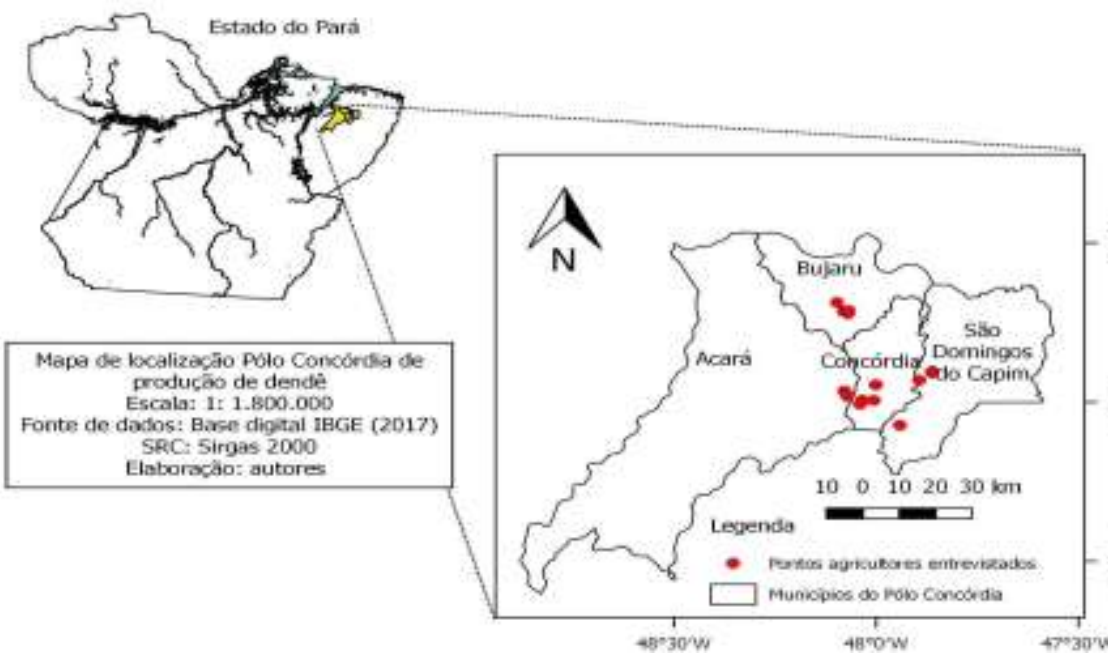
Figura 1: Mapa de localização da área de estudo.

Atualmente, de acordo com o Instituto Brasileiro de Geografia e Estatística (IBGE) (https://www.ibge.gov.br/), a população dos municípios de Acará, Bujaru, Concórdia e São Domingos do Capim, são estimadas em 54.096, 28.331, 32.395 e 31.123 mil habitantes respectivamente. $\mathrm{O}$ número de habitantes bem como sua distribuição entre zona urbana e rural é apresentado na tabela 1.

Tabela 1: População urbana, rural e total dos municípios da área de estudo

\begin{tabular}{c|c|c|c}
\hline Município & População urbana & População rural & População total \\
\hline Acará & 12.621 & 40.948 & 53.569 \\
\hline Bujaru & 8.099 & 17.596 & 25.695 \\
\hline Concórdia & 15.088 & 13.128 & 28.216 \\
\hline São Domingos do Capim & 6.589 & 23.257 & 29.846 \\
\hline
\end{tabular}

A economia do nordeste paraense está centrada na agricultura de subsistência tanto de base familiar quanto comunitária na qual a produção excedente é comercializada). Há algumas décadas, as áreas destinadas aos sistemas produtivos da agricultura familiar eram cobertas por florestas com uma rica biodiversidade. Entretanto, hoje há a predominância de pastagens degradadas e vegetação em vários estágios sucessionais devido à exploração madeireira e necessidade de produção agropecuária (Cordeiro, Vasconcelos, Schwartz \& Oliveira, 2017).

3.2 Coleta e análise de dados.

\subsubsection{Seleção da amostra.}

Para o alcance dos objetivos deste estudo, foi selecionada uma amostra de agricultores familiares que, desde 2010, possuem contrato com a empresa que atua no cultivo de dendê, cedendo suas propriedades para o cultivo e estabelecendo uma relação de remuneração por produção. De acordo com informações levantadas em campo, em 2010 foram firmados 24 contratos com agricultores familiares, com 1 desistência registrada posteriormente. Dos 23 agricultores restantes, foi possível aplicar o formulário em 19, assim distribuídos por município: Acará (3), Bujaru (6), Concórdia (5) e São Domingos do Capim (5). Não foi possível entrevistar os demais agricultores por problemas relacionados à logística e disponibilidade de tempo.

\subsubsection{Aplicação do instrumento de coleta de dados.}

Como instrumento de coleta de dados utilizou-se formulários de entrevista semiestruturados com perguntas abertas e fechadas aos agricultores que concordaram assinar o Termo de Consentimento Livre e Esclarecido (TCLE). O formulário foi construído com os objetivos de realizar uma descrição do perfil socioeconômico dos agricultores e de suas famílias e levantar dados referentes à situação econômica, social e qualidade de vida, no contexto de sua atividade 
atual de produtor de dendê com contrato junto à empresa beneficiadora do óleo de palma. As entrevistas foram realizadas por meio de diálogos presenciais, permitindo a compreensão em relação aos atores sociais e contextos sociais específicos (Marconi \& Lakatos, 2011).

Ao todo foram 3 incursões ao campo que ocorreram no período de agosto a outubro de 2017. A primeira ocorreu no mês de agosto, em visita à Secretaria Municipal de Agricultura (SEMAGRI), no município de Concórdia do Pará onde buscou-se, através de conversas informais com funcionários registradas no diário de campo, compreender a forma como a dendeicultura foi implantada na região. Nesta primeira visita também foram levantadas as informações referentes à empresa produtora de dendê na região e os agricultores familiares que aderiram ao projeto do dendê, com datas de adesão e seus respectivos endereços. Como resultado da primeira visita de campo, obtiveram-se as informações preliminares para elaboração dos formulários de pesquisa.

A segunda visita ocorreu no mês de setembro, com a finalidade de localizar as residências e propriedades dos agricultores familiares, bem como testar os formulários para verificar a adequação das perguntas aos objetivos da pesquisa. Por fim, a última visita ocorreu no mês de outubro, e teve duração de cinco dias durante os quais foram aplicados os formulários aos agricultores e reaplicados aqueles que haviam sido entrevistados na fase de pré-teste. Além disso, foi realizada a marcação das coordenadas geográficas com auxílio de GPS.

\subsubsection{Análise de dados.}

Os dados coletados foram organizados e tabulados a partir das variáveis pré- definidas, e tratados estatisticamente através do pacote estatístico SPSS (Statistical Package for the Social Sciences) versão 20.0. A análise quantitativa dos dados obtidos foi realizada por meio de estatística descritiva, seguida da análise qualitativa que possibilitou uma visão holística das informações coletadas.

\section{RESULTADOS E DISCUSSÕES}

\subsection{Perfil socioeconômico dos entrevistados.}

Em decorrência da grande variação entre os entrevistados, as idades foram divididas em classes parar melhor avaliação (Tabela 2). Sendo assim, 26\% dos agricultores estão na faixa de idade situada entre os 43 e 50 anos, com uma média de 49 anos. Com relação a esses dados, percebe-se uma semelhança com outros estudos que apontaram a presença de uma população mais velha na zona rural como resultado do êxodo de jovens em direção à zona urbana em busca de melhores condições de estudos e ofertas de emprego (Mera \& Mielitz, 2014).

Tabela 2: Idade dos agricultores entrevistados.

\begin{tabular}{l|l|l}
\hline Classes & Fi & Fi\% \\
\hline $29 \mid---36$ & 4 & $21 \%$ \\
\hline $36 \mid---43$ & 2 & $10,6 \%$ \\
\hline $43 \mid--50$ & 5 & $26,3 \%$ \\
\hline $50 \mid---57$ & 3 & $15,7 \%$ \\
\hline
\end{tabular}


Em relação à escolaridade, mais de $70 \%$ dos entrevistados possui apenas o ensino fundamental incompleto (Figura 2). Segundo Silva e Alves (2016) a avaliação do nível de escolaridade é importante devido à parceria entre as empresas ser estabelecida via contrato, sendo essencial que o agricultor compreenda as cláusulas contratuais, assim como a obtenção de conhecimentos necessários para lidar com as inovações técnicas incorporadas ao processo produtivo.

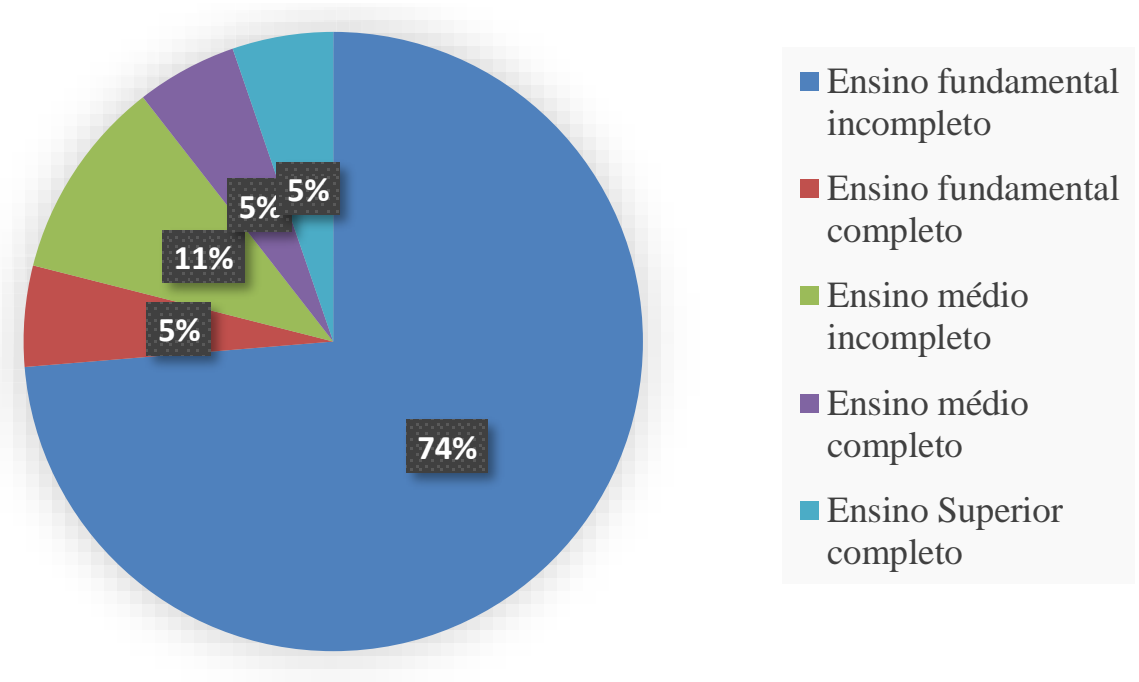

Figura 2: Nível de escolaridade dos agricultores entrevistados

Em relação à contribuição do dendê na renda familiar, a quase totalidade dos entrevistados $(94,7 \%)$ considerou que houve aumento na renda após a integração do dendê. Porém, $47,4 \%$ deles ainda permanecem com os pequenos cultivos na área da propriedade, também conhecidos como roças; $10,6 \%$ possuem plantações de outras culturas (laranja e urucum); $10,6 \%$ criam animais para comercialização (suínos e aves); 15,9\% recebem proventos sociais como aposentadoria e 10,5\% possuem trabalho assalariado como fontes alternativas de renda.

O cenário descrito evidencia que o dendê não é a fonte principal de renda desses agricultores que, portanto, contam com a ajuda de outras fontes para complementar a renda familiar, algumas já desenvolvidas antes de iniciarem as atividades no projeto de integração do dendê. Isso pode ser constatado também a partir da análise de acesso a bens e serviços antes e depois da adesão ao projeto. Em relação ao acesso à energia elétrica, fogão a gás, geladeira, televisão, celular e bicicleta, mais de $80 \%$ dos agricultores afirmaram ter acesso a esses bens antes de trabalharem com o dendê. Da mesma forma, todos os agricultores afirmaram possuir casa própria e acesso a água potável antes da integração do cultivo de dendê.

Ainda que tenha ocorrido o aumento na aquisição de alguns bens e serviços após a integração da agricultura familiar com o dendê, os agricultores não atribuem tal fato à adesão ao projeto dendê. É o que ocorre, por exemplo, em relação a implantação do sistema de irrigação que foi destinado para uso em outras culturas. 
Rodrigues, Conceição, Rodrigues, M. S., Moraes \& Conceição, S. S. (2014) relatam que o aumento no nível da renda familiar não está relacionado somente à produção proveniente da palma de óleo e sim do complemento de diversas atividades, como a criação de pequenos animais (principalmente suínos e aves), culturas alimentares diversas e fruticultura.

Em relação à motivação que levou os agricultores a trabalharem com o cultivo do dendê, destacam-se dois motivos principais: a expectativa de aumento na renda familiar $(42,1 \%)$ e o incentivo por parte da empresa (31,6\%). O terceiro motivo mais citado foi a declinação no plantio de culturas anteriores $(15,8 \%)$. Este último incentivo foi relatado por quatro agricultores, cada qual com um projeto. De acordo com o que foi relatado, a divulgação por parte dos funcionários incentivando o cultivo do dendê coincidiu com o período no qual as plantações cultivadas até então pelos agricultores havia entrando em declínio. Dessa forma, aderir ao projeto do dendê foi a alternativa mais viável encontrada por eles como fonte de renda substitutiva.

A adesão ao projeto do dendê está relacionada principalmente com a ausência de políticas de estado que proporcionem alternativas ao dendê ou pelo menos na dificuldade em acessar aquelas já existentes, isso porque a agricultura familiar parece não dispor de iniciativas que proporcionem o mesmo suporte institucional recebido pela dendeicultura, principalmente no que se refere a garantia de compra do produto a preço de mercado e monitoramento de todas as fases do processo produtivo (Nahum \& Bastos, 2014).

Vale ressaltar que óleo de palma, como citado anteriormente, é bastante valorizado na indústria alimentícia e, portanto, as forças de mercado são atuantes para que o seu preço se mantenha estável e não sofra com excesso de oferta e variações sazonais, o que não ocorre com os produtos tradicionais da agricultura familiar. Destaca-se também a estrutura intensiva em capital, tecnologia e mercadológica excepcionais, quando comparados com o suporte dado às demais culturas.

Com relação ao acesso à serviços de saúde, ações voltadas a educação, segurança e preservação ambiental, não foram constatadas medidas concretas na perspectiva dos agricultores que levem a melhorias significativas na qualidade de vida. De acordo com o que foi relatado nas entrevistas, as poucas ações mencionadas realizadas por parte da empresa, ocorreram apenas nos anos iniciais, mas não foram concluídas.

Em relação à educação, apenas uma medida foi citada pelos agricultores, que consistia em uma biblioteca itinerante com foco no público infantil que circulava por algumas comunidades, mas que foi descontinuada. No que diz respeito a serviços de saúde, segurança e preservação ambiental, as ações se resumem ao treinamento oferecido inicialmente para aplicação de fertilizantes e agrotóxicos e explicações por parte dos técnicos da empresa sobre os possíveis danos que a utilização desses produtos pode provocar na saúde humana e no meio ambiente.

As empresas não são responsáveis pela criação de políticas públicas, mas devem cumprir a responsabilidade social que assumiram com os agricultores familiares parceiros. Segundo Tenório et al. (2011), a responsabilidade social empresarial é necessária em decorrência dos impactos sociais causados pelas atividades dessas companhias. Bertoncello e Chang Junior (2007) afirmam que em 
alguns casos, a responsabilidade social pode estar relacionada à múltiplas exigências que abordam desde as contribuições para o desenvolvimento da comunidade até a conservação ambiental.

4.2 Influência da integração à cadeia produtiva do dendê na agricultura familiar.

As variáveis utilizadas para avaliar a influência da integração à cadeia produtiva do dendê na agricultura familiar (Tabela 3) apresentaram em sua maioria, resultados positivos. Cerca de $80 \%$ dos entrevistados consideraram que houve aumento na valorização da propriedade em decorrência da presença dos dendezais. Em relação à renda bruta e margem de lucro da atividade, mais de $80 \%$ dos agricultores consideraram que houve crescimento, porém ressaltaram que há uma oscilação nos valores por conta da variação na produção nos períodos da safra e entressafra.

Tabela 3: Influência da integração à cadeia produtiva do dendê na área de estudo.

\begin{tabular}{l|l|l|l}
\hline \multicolumn{1}{c|}{ Variável explicativa } & Crescimento & Diminuição & Sem alteração \\
\hline Valor da propriedade & $78,9 \%$ & $10,5 \%$ & $10,5 \%$ \\
A renda bruta da atividade & $84,2 \%$ & $10,5 \%$ & $5,3 \%$ \\
A margem de lucro da atividade & $84,2 \%$ & $10,5 \%$ & $5,3 \%$ \\
Ocupação de mão de obra familiar & $26,3 \%$ & $68,4 \%$ & $5,3 \%$ \\
Qualidade das condições de trabalho & $42,1 \%$ & $47,4 \%$ & $10,5 \%$ \\
Segurança alimentar/cultivo conjugado & - & $78,9 \%$ & $21,1 \%$ \\
Uso de mudas e sementes melhoradas & $94,7 \%$ & - & $5,3 \%$ \\
Uso de pesticida, herbicida ou fungicida & $63,2 \%$ & $15,8 \%$ & $21,1 \%$ \\
Uso de tecnologia & $94,7 \%$ & - & $5,3 \%$ \\
Acesso a crédito & $100 \%$ & - & - \\
Assistência técnica & $100 \%$ & - & - \\
Acesso a informações sobre questões ambientais & $100 \%$ & - & - \\
\hline
\end{tabular}

No que diz respeito à ocupação da mão-de-obra familiar, constatou-se que houve diminuição. De acordo com as informações obtidas em campo, essa diminuição possui duas causas principais: o êxodo rural de parte da família, na maioria referente aos jovens; e à demanda no trabalho do dendê que a partir do terceiro ano passa a diminuir. Apesar dessa diminuição na ocupação da mão-de-obra familiar, 100\% dos entrevistados afirmaram ter necessidade de pagar 1 a 4 diaristas nos períodos de corte e colheita.

Nahum e Santos (2017) mencionam que em decorrência da intensidade e diversidade do trabalho muitas famílias buscam força de trabalho exterior ao núcleo familiar. Verificou-se em trabalho de campo que $70 \%$ dos entrevistados utilizam mão- de-obra familiar e $30 \%$ contratam força de trabalho do consórcio de mão-de-obra. É importante ressaltar que na pesquisa realizada pelos autores, a maioria das famílias eram numerosas, diferentemente do presente estudo no qual o número máximo encontrado foi de seis integrantes.

Com relação à qualidade nas condições de trabalho, $47 \%$ dos entrevistados alegaram haver diminuição em decorrência das exigências demandadas pelo cultivo do dendê, principalmente nos três primeiros anos da cultura. A segurança alimentar apresentou diminuição em decorrência da necessidade de diminuir a quantidade produzida de outras culturas. 
Entre os cultivos realizados antes da integração com o dendê, destacam-se a mandioca (cultivada por $84,2 \%$ dos agricultores) e a pimenta-do-reino (cultivada por $73,7 \%$ dos agricultores). A mandioca é cultivada principalmente para produção de farinha voltada para subsistência e em alguns casos para comercialização no mercado local. Já a pimenta-do-reino possui destinação para o comércio local e também para outros municípios. Outras culturas foram citadas em uma escala menor.

Para Fernandes (2016), as culturas anuais como a mandioca estão diretamente relacionadas ao consumo familiar, sendo apenas o excedente da produção vendido. Ou seja, esses cultivos estão relacionados à segurança alimentar, uma vez que a produção proveniente da roça diminui ou elimina a necessidade da compra dessas plantações alimentares.

Nesse aspecto, um dos questionamentos levantados sobre a dendeicultura no nordeste paraense é a especialização da atividade em detrimento da produção de culturas alimentares, uma vez que a utilização de capoeira para plantação do dendê diminui a área destinada a cultura como a mandioca. Na pesquisa realizada pelos autores, $24 \%$ dos agricultores entrevistados declararam ter parado de trabalhar com roça devido à falta de mão-de-obra e o cumprimento dos termos a serem cumpridos no contrato e $15 \%$ pararam de trabalhar com a cultura por não possuir mão-de-obra suficiente para as duas atividades (Silva \& Alves, 2017a).

Estudos realizados por Mota, Silva, Schmitz, Alves \& Ferreira (2015), constataram que 24\% dos agricultores entrevistados não possuíam culturas anuais em suas propriedades devido à necessidade de dedicação exclusiva ao dendê em decorrência da escassez de mão-de-obra e dos compromissos contratuais, evidenciando a diminuição na produção de culturas alimentares em detrimento da produção de dendê.

Devido à adesão ao cultivo do dendê, $68,4 \%$ dos agricultores entrevistados afirmaram que houve a necessidade de diminuir a quantidade das culturas cultivadas anteriormente. Segundo eles, isso ocorre por dois fatores: o aumento da área que passa a ser cultivada, uma vez que são destinados 10 hectares de terra para a plantação do dendê, e as exigências dessa cultura durante os três primeiros anos, o que acaba demandado mais tempo e atenção para o cultivo do dendê.

Em relação ao uso de defensivos agrícolas, de acordo com 63,2\% dos entrevistados, o uso de pesticida, herbicida ou fungicida aumentou após a adesão ao cultivo do dendê. Isso porque esses produtos são utilizados incialmente para cessar o crescimento de plantas que concorrem por espaço com o dendê e para evitar doenças e aparecimento de parasitas.

O uso indiscriminado de pesticida pode desencadear danos como o prejuízo a saúde em decorrência da exposição direta ou indireta aos compostos químicos; contaminação das águas subterrâneas e superficiais em decorrência do escoamento e infiltração; a transmissão de resíduos tóxicos através da cadeia alimentar; o aumento na resistência de populações de pragas e a redução de microrganismos no solo (Pingali \& Roger, 2012).

Houve aumento também no uso de tecnologia, sendo o trator o instrumento mais citado como principal aquisição para auxiliar na colheita e roçagens, o qual foi adquirido pela maioria dos entrevistados após a integração com o cultivo do dendê. Silva e Alves (2017b) relatam que, na 
concepção de muitos agricultores, a integração com o cultivo da palma representa a modernização por meio da mecanização agrícola, acesso ao crédito e assistência técnica.

Em relação ao acesso a crédito, assistência técnica e acesso a informações sobre questões ambientais, todos os entrevistados afirmaram haver crescimento em relação a essas variáveis. $A$ facilidade de acesso ao crédito deve-se à participação no projeto em conjunto com a empresa.

No que diz respeito à assistência técnica e informações sobre questões ambientais considera-se que houve crescimento uma vez que na prática das culturas cultivadas anteriormente, os agricultores não desfrutavam da visita de técnicos, como ocorre eventualmente por parte da empresa e que não possuíam informações sobre as consequências que práticas como a queimada poderiam ter sobre o solo e a própria plantação.

4.3 Alterações nos aspectos socioambientais observados antes e depois da estruturação da cadeia produtiva do dendê

Em relação à prática de queimada, por exemplo, cerca de $90 \%$ dos agricultores a realizavam em suas propriedades antes de cultivarem o dendê. Após a adesão ao projeto, essa porcentagem caiu para $52,6 \%$ de agricultores que utilizam queimadas nas áreas destinadas as suas plantações. Entretanto, os que realizam essa prática afirmaram que não a utilizam nas áreas destinadas ao dendê, uma vez que isso compromete seu crescimento e consequentemente interfere na produção.

A maioria dos agricultores não tinha instruções ou informações a respeito da aplicação de defensivos agrícolas e fertilizantes até a integração com o cultivo do dendê. Apenas um agricultor $(5,3 \%)$ relatou já ter realizado curso sobre essa aplicação antes de trabalhar na dendeicultura. Os $94,7 \%$ restantes só tiveram acesso a esse treinamento a partir da visita de técnicos da empresa com a qual participam do projeto.

Segundo estudos de Chaves e Magalhães (2016), os agricultores entrevistados consideraram como ponto crucial o fornecimento do curso de capacitação por parte da empresa em relação a aplicação de agrotóxicos que possibilitaram também o entendimento sobre os impactos desses produtos sobre a saúde humana, fazendo com que os agricultores passassem a ser mais responsáveis com o seu uso.

Em relação a tripla lavagem de embalagens de agrotóxicos, local adequado para armazenagem de produtos químicos e utilização de equipamento de proteção individual (EPI), antes da adesão ao projeto, apenas $10,5 \%$ dos entrevistados realizavam a lavagem das embalagens e nenhum dos agricultores possuía local adequado para armazenar os produtos químicos, além disso apenas 5,3\% utilizavam EPI. Após a integração à cadeia produtiva do dendê, todos os agricultores afirmaram que passaram a realizar a tripla lavagem das embalagens; $84,2 \%$ afirmou ter local adequado para armazenamento de produtos químicos e $94,7 \%$ passou a utilizar EPI.

No que se refere ao local adequado para armazenamento dos produtos químicos e utilização de EPI é importante ressaltar que a perspectiva dos agricultores é diferente da considerada em termos de legislação. Para os agricultores e de acordo com o que foi observado durante as entrevistas, esse local refere-se à uma construção simples, em sua maioria de madeira, geralmente 
localizada ao lado da residência do agricultor. E em relação aos equipamentos de proteção individual, geralmente considera-se a bota, luvas e óculos de proteção.

De acordo com norma brasileira [NBR] 9843-3 de 2013, da Associação Brasileira de Normas Técnicas [ABNT], o armazenamento de agrotóxicos e afins em propriedades rurais, apresenta como exigências que o local de armazenamento deve estar em locais livres, distantes de moradias e cursos d'água. Além disso, deve ser construído em alvenaria ou material que não propicie a propagação de chama, com piso que facilite a limpeza e não permita a infiltração.

Em relação aos equipamentos de proteção individual, a Norma Regulamentadora [NR] 6, indica que de acordo com as peculiaridades de cada atividade, os trabalhadores devem ter acesso a EPI destinados à proteção de cabeça (capacetes ou protetores de cabeças impermeáveis), dos olhos e da face (óculos de segurança); das vias respiratórias (respiradores com filtros e máscaras), dos membros superiores (luvas e mangas de proteção), membros inferiores (botas e perneiras) e do tronco (aventais, jaquetas e capas) (Brasil, 20017).

Ainda que essas normas sejam exigidas em atividades que haja vínculo empregatício legal (caso que não se constata na integração entre a dendeicultura e a agricultura familiar) é sempre importante ter em mente a responsabilidade social por parte das empresas, já discutida anteriormente.

A utilização de agrotóxicos e fertilizantes gera importantes questionamentos no que diz respeito às embalagens utilizadas para armazená-los. Dessa forma, os agricultores foram questionados sobre a devolução das embalagens. A partir desse questionamento, constatou-se que dos 19 agricultores entrevistados, 89,5\% não realizam a devolução das mesmas. Apenas 10,5\% efetuam a devolução por intermédio da empresa, que de acordo com eles, realiza a coleta das embalagens (Figura 3).

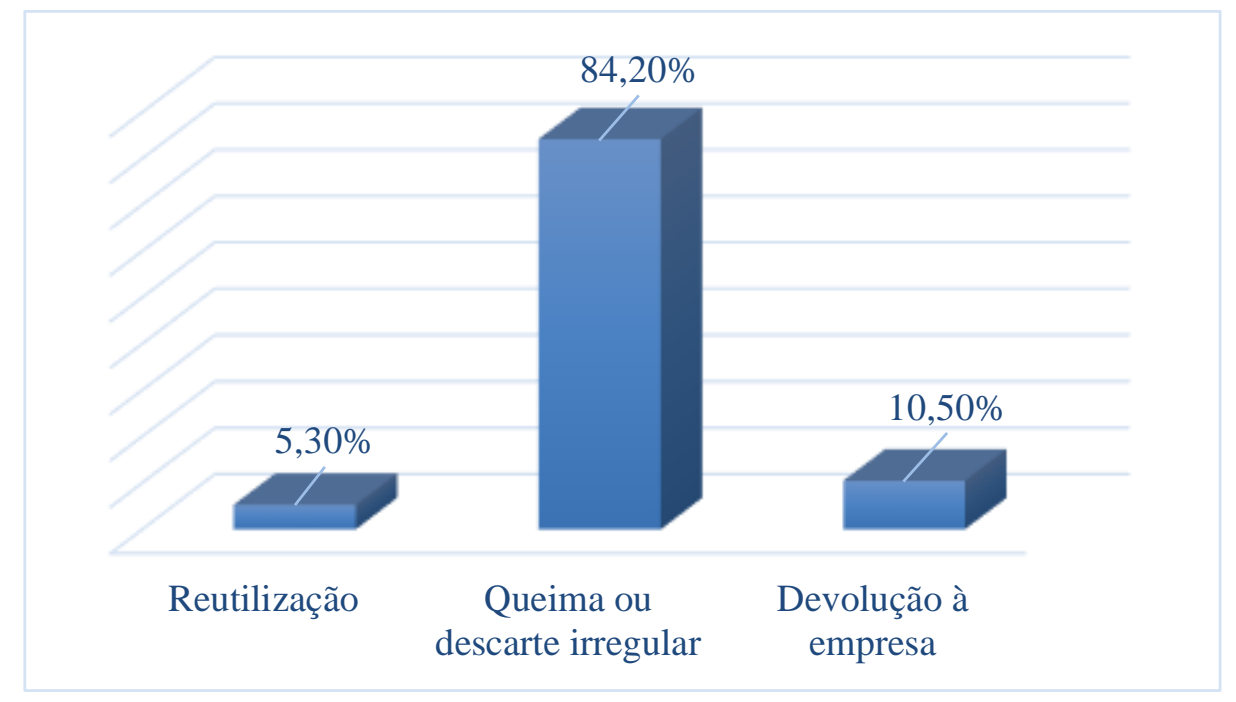

Figura 3: Destinação das embalagens de agrotóxicos.

A partir do fato da maioria não realizar a devolução das embalagens, outro questionamento foi feito em relação a destinação que os agricultores adotavam como alternativa para eliminar esses 
resíduos. Constatou-se então, que $84,2 \%$ dos agricultores queimam ou descartam incorretamente as embalagens de agrotóxicos e fertilizantes. E que 5,3\% as utilizam para outros fins. Essas ações são consideradas impróprias de acordo com normas e legislações.

A destinação final de embalagens de agrotóxicos é regulamentada pela lei 7.802, de 11 de julho de 1989 que determina a devolução das embalagens vazias dos produtos diretamente ou por intermédio de postos ou centros de recolhimentos aos estabelecimentos comerciais em que foram adquiridos. Em relação às embalagens rígidas que apresentarem características como solubilidade ou dispersão em água devem ser submetidas pelo usuário à operação de tríplice lavagem ou tecnologia semelhante.

O descarte inadequado dessas embalagens é prejudicial à saúde humana e ao meio ambiente por conter resíduos de substâncias químicas que podem modificar o ambiente nas suas mais diferentes formas de vida. Essas características enquadram esses resíduos na categoria de resíduos perigosos, que podem comprometer definitivamente a cadeia natural, contaminar o solo, a água e o ar (Oliveira \& Sabonaro, 2016).

Os impactos sociais causados pela dendeicultura integrada à agricultura familiar ocorrem nos mais variados âmbitos. Piraux, Rapiau e Timone (2017) elencam problemas que envolvem desde a dependência em relação aos bancos até a fragilização da vida comunitária.

A dependência devido ao contrato de 25 anos com a empresa implica em consequências que vão bem além da esfera econômica. Essa relação faz com que muitos agricultores percam a identidade e não se reconheçam mais como agricultores familiares devido a fatores como a perda da autonomia sobre o processo produtivo e a terceirização da mão-de-obra (Piraux, Rapiau e Timone, 2017).

Segundo Nahum (2013), a integração com a dendeicultura resulta em alterações na paisagem, na configuração social, na dinâmica social e no território. O ambiente que antes era destinado à produção de atividades da unidade familiar passa a ser constantemente associado e dependente das atividades relacionadas ao cultivo do dendê.

Se antes esses agentes tinham controle quanto às culturas que plantavam, o modo de plantio e colheita, bem com a mão-de-obra empregada, a partir da integração passam a ser agentes passivos submetidos às ordens e demandas da empresa. Passa-se a ter a necessidade de utilização de novas técnicas, contratação de mão-de-obra e as atividades antes realizadas pelo núcleo familiar ficam em segundo plano.

Outro aspecto preocupante da integração diz respeito à relação de trabalho entre a empresa e o agricultor. As unidades familiares integradas ao processo não são consideradas mão-de-obra assalariada e por isso não possuem direitos trabalhistas, ainda que suas propriedades sejam usadas quase que exclusivamente para a cultura do óleo de palma (Nahum, 2013).

\section{CONCLUSÕES}

No presente estudo, considerando-se as áreas analisadas, compreendeu-se que a dendeicultura contribui para a geração de renda no núcleo familiar. Todavia, essa contribuição ainda 
não apresenta caráter significativo, fazendo com que os agricultores familiares continuem desempenhando atividades econômicas paralelas para complementar a renda.

Admite-se que alguns pontos positivos foram atingidos após a inserção dos agricultores familiares, como o acesso à assistência técnica e informações sobre questões ambientais que até então, muitos desses atores não detinham. Mas, é importante ressaltar que essa prestação de serviço deve ocorrer de maneira contínua para que os agricultores possam estar cada vez mais capacitados e familiarizados com as novas tecnologias.

Em contrapartida, o aumento no uso de defensivos agrícolas teve como consequência o aumento na geração de resíduos sólidos perigosos, por meio da queima e descarte incorreto de embalagens que provocam riscos ao meio ambiente e à saúde humana. A situação foi agravada pela reutilização de embalagens laváveis para outros fins por parte de uma pequena parcela de agricultores. É necessário que a empresa promova junto aos agricultores medidas que possibilitem o armazenamento adequado dessas substâncias bem como sua correta destinação final.

A princípio, a perspectiva por trás da dendeicultura sob a ótica da sustentabilidade e inclusão social é bastante interessante e atrativa. Porém, é importante avaliar as condições estruturais nas quais os agricultores familiares se encontram, uma vez que o arranjo de mão-de-obra familiar não está preparado para a mudança repentina de modalidade para o cultivo da monocultura em decorrência de suas áreas extensas e utilização de novas técnicas. É importante também que sejam planejadas políticas públicas que ofereçam ao agricultor familiar uma alternativa frente o cultivo do dendê.

Seria interessante avaliar o processo de produção do dendê do ponto de vista da sustentabilidade, avaliando as fases do ciclo produtivo a fim de identificar possíveis falhas e desperdícios de insumos, sendo possível analisá-los e propor dessa forma medidas mitigadoras que representassem benefícios sociais, econômicos e ambientais.

\section{REFERÊNCIAS}

ALBANO, G. P. (2012). Globalização da agricultura na Oceania: óleo de palma, a última fronteira. Revista Geotemas, 2(1), 37-59.

ALVES, R. N. B., MODESTO, S. M. Jr., MAGALHÃES, J., \& BANDEIRA, B. (2016). Análise comparativa dos custos de implantação do cultivo de dendê solteiro e consorciado com mandioca. Revista Amazônia Ciência e Desenvolvimento, 12(22), 9-20.

AQUINO, S, L, de. (2013). Estratégias empresariais e efeitos locais: A integração de pequenos agricultores à indústria fabricante de papel e celulose. Revista IDEAS, 7, 158-197.

Associação Brasileira de Normas Técnicas (2013). NBR 9843-3: Agrotóxicos e afins: armazenamento em propriedades rurais. Rio de Janeiro: Autor.

BACKHOUSE, M. A. (2013). A desapropriação sustentável da Amazônia: O caso de investimentos em dendê no Pará [Working Paper № 6]. Ministério Alemão da Educação e Pesquisa Cientifica, Berlim, Alemanha. 
BELTRÃO, N. E., \& OLIVEIRA, M. I. (2008). Oleaginosas e seus óleos: Vantagens e Desvantagens para Produção de Biodiesel (p. 28). Campina Grande: EMBRAPA.

BERTONCELLO, S. L. T., \& CHANG, J., Jr. (2007). A importância da Responsabilidade Social Corporativa como fator de diferenciação. Revista FACOM, (17), 70-76.

BORGES, A. M., BONOW, C. A., SILVA, M. R. S., ROCHA, L. P., \& CEZAR-VAZ, M. R. (2016). Agricultura familiar e conservação da saúde humana e ambiental. Revista Brasileira de Enfermagem, 69(2), 326334.

BRANDÃO, F., \& SCHONEVELD, G. (2015). The state of oil palm development in the Brazilian Amazon: Trends, value chain dynamics, and business models (p. 54). Indonésia: CIFOR.

BRASIL. (2004). Decreto no 5.297 de 6 de dezembro de 2004. Dispõe sobre os coeficientes de redução das alíquotas da Contribuição para o PIS/PASEP e da COFINS incidentes na produção e na comercialização de biodiesel, sobre os termos e as condições para a utilização das alíquotas diferenciadas, e dá outras providências. Brasília, DF. Recuperado em 30 novembro, 2017, de http://www.planalto.gov.br/ccivil_03/_ato2004-2006/2004/decreto/d5297.htm.

BRASIL. (2017). Ministério do Trabalho e Emprego. NR 6 - Equipamentos de Proteção Individual. Brasília, DF. Recuperado em 30 novembro, 2017, de http://trabalho.gov.br/images/Documentos/SST/NR/NR6.pdf.

BRUNO, Regina. (2016). Desigualdade, agronegócio, agricultura familiar no Brasil. Estudos Sociedade e Agricultura, 24(1), 142-160.

CARVALHO, A. C. A., NASCIMENTO, E. N., \& NAHUM, J. S. (2014, setembro). A dendeicultura e sua expansão no estado do Pará: uma interpretação geográfica do evento. Anais do Congreso Ibero Americano de Estudios Territoriales y Ambientales, São Paulo, Brasil, 6.

CHAVES, G. P., \& MAGALHÃES, S. B. (2016, agosto). Percepção de riscos e implicações socioculturais: uma análise sobre o uso de agrotóxicos por camponeses integrados à agroindústria do dendê no Estado do Pará. Anais da Reunião Brasileira de Antropologia, João Pessoa, Paraíba, Brasil, 23.

CORDEIRO, I. M. C. C.; VASCONCELOS, L. G. T. R., SCHWARTZ, G., \& OLIVEIRA, F.A. (2017). Nordeste Paraense: panorama geral e uso sustentável das florestas secundárias (p. 323). Belém: EDUFRA.

CORLEY, R. H. V., \& TINKER, P. B. H. (2015). The oil palm (5nd ed., p. 680). India: Wiley-Blackwell.

CRUZ, B., \& ROCHA, G. (2007). Dendê como projeto de Estado: uma alternativa econômica, social e ecológica para a Amazônia. Anais do Encontro de Geógrafos da América Latina, Colômbia,11.

DIETZ, K., ENGELS, B., PYE, O., \& BRUNNENGRÄBER, A. (Eds.). (2015). The political ecology of agrofuels (p. 278). New York: Routledge.

FERNANDES, T. (2016). Relatório de monitoramento dos indicadores de sustentabilidade: agricultura familiar e produção de palma (p. 79). Belém: Instituto Peabiru. 
FITZHERBERT, E. B.; STRUEBIG, M. J., MOREL, A., DANIELSEN, F., BRÜHL, C. A., DONALD, P. F., \& PHALAN, B. (2008). How will oil palm expansion affect biodiversity. Journals Trends in Ecology and Evolotion, 23(10), 538-545.

Food and Agriculture Organization of the United Nations (2014). Faostat online database. Recuperado em 25 novembro, 2017, de http://www.fao.org/faostat/en/\#data/QC.

Fundação Amazônia de Amparo a Estudo e Pesquisa. (2015). Boletim Agropecuário do Estado do Pará 2015 (p. 38). Belém: Autor.

GEMAQUe, A. M. S., BELTRÃO, N. E. S., MESQUitA, M. O. B., \& FERREIRA FILHO, H. R. (2017). Qualidade de vida do agricultor familiar e sua relação com a dendeicultura: estudo de uma comunidade rural no município de Moju, Pará. Revista Brasileira de Gestão e Desenvolvimento Regional, 13(1), 174197.

HOMMA, A. K. O. (2016). Cronologia do cultivo do dendezeiro na Amazônia (p. 48). Belém: Embrapa.

LEBID, T., \& HENKES, J. (2015). O óleo de dendê na produção de biodiesel: um estudo de caso das vantagens e desvantagens econômica, ecológica e social da cultura desta oleaginosa para a produção de biodiesel. Revista Gestão e Sustentabilidade Ambiental, 4(1), 392-415.

MARCONI, M. A., \& LAKATOS, E. M. (2011). Metodologia científica (6a ed.). São Paulo: Atlas.

MERA, C. M. P., \& MIELITZ NETTO, C. (2014). Envelhecimento dos produtores no meio rural na região do alto Jacuí/RS e consequente migração para cidade. Revista do Núcleo de Estudos interdisciplinares sobre Envelhecimento, 19(3), 759-774.

MITCHELL, D. (2010). Biofuels in Africa: Opportunities, prospects, and challenges (p. 216). Washington: World Bank.

MOTA, D. M., SILVA, E. M., SCHMITZ, H., ALVES, L. N., \& FERREIRA, M. S. G. (2015, novembro). Produção de culturas alimentares e dendê nos estabelecimento familiares no nordeste paraense. Anais do Seminário Internacional América Latina, Belém, Pará, Brasil, 9.

NAHUM, J, S. (2013). Dendeicultura de energia e agricultura familiar na Amazônia Paraense: A microrregião de Tomé-Açu. Revista Terceira Margem Amazônia, 1(3-4), 237-246.

NAHUM, J. S., \& BASTOS, C. S. (2014). Dendeicultura e descampesinização na Amazônia paraense. Revista de geografia agrária, 9(17), 469-485.

NAHUM, J. S., CARVALHO, A. C. A., BASTOS, C. S., CARVALHO, J. S., RIBEIRO, M. S., \& VIEIRA, L. L. (2014). Dendeicultura e dinâmicas territoriais do espaço agrário na Amazônia paraense (p. 158). Belém: UFPA.

NAHUM, J., \& SANTOS, C. B. (2016). A dendeincultura na Amazônia paraense. Revista Geousp - Espaço e Tempo, 20(2), 281-294.

NAHUM, J., \& SANTOS, C. B. (2017). Do sítio camponês ao lote de dendê: transformações do espaço rural na Amazônia paraense no século XXI. Revista NERA, 20(37), 54-76. 
OLIVEIRA, M. M., \& SABONARO, D. Z. (2016). Logística reversa e o processo de destinação das embalagens vazias de agrotóxico. Revista da Universidade Vale do Rio Verde, 14(2), 377-383.

PARÁ (2010). Atlas de Integração Regional do Estado do Pará (p. 347). Belém: SEIR.

PENA, M. A. G. Jr. (2011). Demandas de pesquisa para a Amazônia Legal (p. 348). Brasília: Embrapa.

PINGALI, P. L., \& ROGER, P. A. (2012). Impacts of pesticides on farmer health and the rice environment ( $p$. 664). France: Springer Science \& Business Media.

PIRAUX, M., RAPIAU, J., TIMONE, E. (2017). Percepções dos atores locais sobre a cultura do dendê na agricultura familiar na Amazônia oriental brasileira. Revista Agricultura familiar: Pesquisa, Formação e Desenvolvimento, 11(2), 57-70.

RAMALHO FILHO, A. (2010). Zoneamento Agroecológico, produção e manejo para a cultura da Palma de Óleo na Amazônia (p. 2016). Rio de Janeiro: Embrapa solos.

REDIN, E. (2010). A fumicultura e agricultura familiar: o caso de Jaguari/RS. Revista Sociais e Humanas, 23(2), 99-116.

RODRIGUES, T. C. A., CONCEIÇÃO, S. S., ROdRIGUES, M. S., MORAES, M. C. CONCEIÇÃO, S. S. (2014). Palma de óleo e a agricultura familiar: estudo de caso de um assentamento rural no estado do Pará. Enciclopédia Biosfera, 10(19), 1426-1436.

SILVA, E. M., \& ALVES, L. N. (2016). Os fatores de repercussão da cadeia produtiva do dendê no desenvolvimento local do Baixo Tocantins. Revista Desenvolvimento e Meio Ambiente, 39, 173-188.

SILVA, E. M., \& ALVES, L. N. (2017a). A ocupação do espaço pela dendeicultura e seus efeitos na produção agrícola familiar na Amazônia Oriental [Versão eletrônica]. Revista Confins (30).

SILVA, E. M., \& ALVES, L. N. (2017b). Transformações nos sistemas de produção familiares diante a implantação do cultivo de dendê na Amazônia Oriental. Revista Desenvolvimento e Meio Ambiente, 40, 345-364.

SILVA, J. A. (2013). Avaliação do Programa Nacional de Produção e Uso do Biodiesel no Brasil - PNPB. Revista de Política Agrícola, 22(3), 18-23.

SOARES, A. J. T. (2015). Conhecendo o Pará (p. 144). Belém: Cultural Brasil.

TENÓRIO, F. G., NASCIMENTO, F. C. P., FARES, J., FERRARI, J., VILLAR, L. B., BARROS, R. P. M., HILST, S. M., \& LAZARI, S. (2011). Responsabilidade social empresarial: teoria e prática (2a ed., p. 260). Rio de Janeiro: FGV.

VARGAS, L. P., \& SPANEVELLO, R. M. (2010). Agricultores familiares: caracterização do sistema de integração suinícola os impasses atuais em torno da continuidade da atividade. Anais do Congresso Sociedade Brasileira de Economia e Sociologia Rural. Campo Grande, MS, Brasil, 14.

VERHEYE, W. H. (2010). Soils, plant growth and crop production (Vol. 2, p. 454). United Kingdom: Eolss. 
VILLELA, A. A., JACCOUD, D. B., ROSA, L. P., FREITAS, M. V. (2014). Status and prospects of oil palm in the Brazilian Amazon. Journals Biomass and Energecy, (67), 270-278.

ZALUSKI, P, R, S., MARQUES, I, C. (2015, outubro). Vantagens e Desvantagens do Sistema de Integração Vertical na Avicultura de Corte. Anais do Encontro Nacional de Engenharia de Produção, Fortaleza, CE, Brasil, 16.

ZIMMERMANN, C. L. (2009). Monocultura e transgenia: impactos ambientais e insegurança alimentar. Revista Veredas do Direito, 6(12), 79-100. 